Rev.MVZ Córdoba 16(2):2433-2434, 2011.

\title{
EDITORIAL
}

\section{Ratas, ácaros, guerras, pobreza, negligencia y rickettsiosis}

\section{Rats, mites, wars, poverty, negligence and rickettsioses.}

La historia de las infecciones ha descrito el papel decisivo que jugó el tifus en las guerras. Tal vez el más antiguo y documentado es el sitio de Granada (España) por parte de los católicos contra los árabes en el año 1489, donde se cree que murieron alrededor de 17.000 personas por rickettsiosis; seis veces más que el número de muertos en combate (1). Ya en el año de 1812, durante la toma de Moscú por parte de Napoleón y sus tropas, murieron más soldados por causa del tifus que por las balas de los rusos. Cien años más tarde, en la primera guerra mundial, el tifus fue el responsable de la muerte de más de 3 millones de personas de personas (2).

La gran población de ratas y su carga de ácaros asociada a la pobreza producida por las guerras, así como a la ausencia de servicios públicos, provocó sin duda una alta mortalidad en la población. Tanto la situación de hacinamiento creada por las guerras, como la ausencia de medidas higiénicas facilitaron sin duda la proliferación de roedores y sus ectoparásitos que diseminaron el tifus con una alta mortalidad tanto en soldados como en la población civil. Solo hasta el año 1909 Charles Nicole logró implicar a los piojos como los vectores de la infección (3). Años más tarde, los investigadores Howard Ricketts y Von Prowazek, prácticamente se inmolaron y siguiendo los postulados de Koch murieron de tifus y descubrieron el agente etiológico, los cuales adquirieron su nombre (4).

Las rickettsiosis son cosmopolitas; hoy día son un problema de salud pública y se constituyen en una complicación sanitaria de gran impacto sino son tratadas a tiempo. Colombia fue uno de los primeros países en reportar la enfermedad en Latinoamérica. Los primeros casos se presentaron en la población de Tobia, un municipio del departamento de Cundinamarca, y desde entonces se denominó fiebre de Tobia (5). Entre 1934 y 1936 se documentaron 65 personas víctimas de la enfermedad, 62 casos fueron fatales ( $95 \%$ mortalidad). No obstante, la enfermedad se mantuvo en silencio cerca de 70 años (5).

Motivados por el desconocimiento de esta enfermedad en Colombia, la Universidad de Córdoba realizó en el año 2001 un estudio de seroprevalencia de Rickettsia sp en trabajadores del campo en la zona rural del municipio de Ciénaga de Oro, Córdoba, donde se encontró que 49\% de los sujetos presentaron anticuerpos. La alta seroprevalencia encontrada en el área demostró la circulación de una rickettsia del grupo de las fiebres manchadas y la necesidad de profundizar en este campo (6). Posteriormente en 2004, la Universidad de Córdoba realizó otro estudio de seroprevalencia de Rickettsia sp, pero esta vez en el departamento de Sucre, donde se encontró una seroprevalencia de 7.7\% (7). A partir de estos estudios se despertó cierto interés en el tema, y es así como en el año 2005 en Villeta (Cundinamarca) se reportó una seroprevalencia del $40 \%$ (8). No obstante, estos hallazgos pasaron desapercibidos para las autoridades de salud y para la comunidad en general.

Con tantas cosas que atender en el país, solo se prestó atención en el año 2006 cuando se comprobaron las muertes de algunos militares y civiles en el municipio de Necoclí (Antioquia), como producto de un brote de fiebre hemorrágica (9). Un año más tarde, a unos $100 \mathrm{~km}$ de Necoclí, se presentó un brote de fiebre de origen desconocido en el municipio de Los Córdobas (Córdoba), el cual inicialmente fue atribuido a dengue hemorrágico, aunque finalmente se comprobó como rickettsiosis (10). En el año 2008, en el corregimiento Alto de Mulatos en el municipio de Turbo (Antioquia), se informó sobre la muerte de cuatro personas (letalidad 26.6\%), tres de las cuales eran menores de edad; confirmándose los casos como rickettsiosis (11). 
De otro lado, aunque no hemos padecido guerras mundiales, vivimos un conflicto interno (obstinadamente negado por algunos) y la mitad de los colombianos viven por debajo de la línea de la pobreza sin servicios públicos, por lo que son frecuentes la presentación de patologías como la leptospirosis y la rickettsiosis entre otras.

Hemos visto un breve recuento cronológico de la rickettsiosis en Colombia, sin embargo hay cientos de reportes en Latinoamérica, el Caribe, España y Portugal, que jamás han sido recopilados en forma sistemática. En ese sentido, en este número de la Revista MVZ Córdoba, se presenta por primera vez en la historia de la literatura científica de Latinoamérica, un trabajo retrospectivo que de manera ordenada y documentada resume la epidemiología, la ecología de vectores y los casos de infecciones producidas por Rickettsia. El responsable de este importante trabajo fue la Red Iberoamericana para la Investigacion y Control de las Enfermedades Rickettsiales (RIICER), entidad a la que le reconocemos este innegable aporte que deberá servir para impulsar el estudio de las rickettsias en Latinoamérica y el Caribe.

Finalmente, la Revista MVZ Córdoba, como una primera aproximación hacia el continuo camino de la internacionalización de una revista científica, publica de forma bilingüe el artículo "Rickettsiosis en América Latina, el Caribe, España y Portugal" el cual pone a disposición de los lectores abriendo el presente número.

Marco González T. M.Sc.

Salim Mattar V. Ph.D.

\section{REFERENCIAS}

1. Zinsser, H. Rats, Lice and History. New York: Little Brown and Co; 1935.

2. Snyder JC. Typhus Fever in the Second World War. California Medicine 1947; 66(1)3-10.

3. Nicolle C, Comte C, Conseil L. Transmission expérimentale du typhus exanthématique par le pou du corps. Comptes Rendus Hebdo-Madaires des Séances de l'Académie des Sciences 1909; 149:486-9.

4. Gross D, Schäfer G. 100th Anniversary of the death of Ricketts: Howard Taylor Ricketts (1871-1910). The namesake of the Rickettsiaceae family. Microbes Infect 2011; 13(1):10-3.

5. Patino L, Afanador A, Paul JH. A spotted fever in Tobia, Colombia. Am J Trop Med Hyg 1937; 17:639-653.

6. Miranda A, Flores S, Máttar S. Alta seroprevalencia de rickettsiosis en trabajadores del campo en el Municipio de Ciénaga de Oro, Córdoba. Inf Quinc Epidemiol Nac 2002; 7:65-80.
7. Ríos R, Franco S, Mattar S, Urrea M, Tique V. Seroprevalencia de Leptospira sp., Rickettsia sp. y Ehrlichia sp. en trabajadores rurales del departamento de Sucre, Colombia. Infection 2008;12(2):319-23.

8. Hidalgo M, Sanchez R, Orejuela L, Hernandez J, Walker DH, Valbuena G. Prevalence of antibodies against spotted fever group rickettsiae in a rural area of Colombia. Am J Trop Med Hyg 2007; 77(2):378-80.

9. Acosta J, Urquijo L, Díaz A, Sepúlveda M, Mantilla G, Heredia $D$, et al. Brote de rickettsiosis en Necoclí, Antioquia, febreromarzo de 2006. Inf Quinc Epidemiol Nac 2006; 11:177-92.

10. Hidalgo M, Miranda J, Heredia D, Zambrano P, Vesga JF, Lizarazo D, et al. Outbreak of Rocky Mountain spotted fever in Cordoba, Colombia. Mem Inst Oswaldo Cruz 2011; 106(1):117-8.

11. García OEP, Giraldo MR, Duran MM, Hidalgo M, Galeano A, Echeverri I, et al. Estudio de brote febril hemorrágico en el corregimiento de Alto de Mulatos - Distrito Especial Portuario de Turbo, Antioquia, enero de 2008. Inf Quinc Epidemiol Nac 2008; 13(10):145-60. 